\title{
Use of phytoestrogen with clomiphene citrate for ovulation induction in polycystic ovary syndrome
}

\author{
Mohamed Nagi Mehasen ${ }^{a}$, Eman Zein Elabdeen Farid, Ahmed Maged ${ }^{b .}$ and ${ }^{b}$ Azhar Mohamed \\ Farid \\ ${ }^{a}$ Obstetrics and Gynecology department, Faculty of Medicine, Cairo University, Egypt \\ ${ }^{\mathrm{b}}$ Obstetrics and Gynecology department, Faculty of Medicine, Beni-Suef University, Egypt
}

\begin{abstract}
The goal of this study is to assess the effectiveness of phytoestrogen with clomiphene citrate for ovulation induction in women with polycystic ovarian syndrome to overcome the antiestrogenic effect of clomiphene citrate on endometrium, were randomly grouped into two groups, 50 in each group. Group 1: receiving CC $100 \mathrm{mg}$ twice daily from third day of cycle for five days and group 2: receiving CC from 3rd of cycle for 5 days plus phytoestrogen (Klimadynon(®), Bionorica, Neumarkt i.d.OBf., Germany) (20mg of cimifuga racemosa from day 1to12). Women receiving CC plus phytoestrogen have increase number of dominant follicles, endometrial thickness with improvement of both ovulation rate and pregnancy rate.
\end{abstract}

Keywords: Cimicifuga, clomiphene citrate, endometrial thickness, induction, phytoestrogens. 
ovulation induction and fertility treatment in women with PCOS:-

-Weight loss, exercise, and life style modifications.

-It has been more than 50 years that $\mathrm{CC}$ is established as the first line for ovulation induction in PCOS. it is believed to bemore convenient and cost-efficient (7).

It is used for stimulation of ovulation by blocking the estrogen receptors in The hypothalamus and blocking the negative feedback effect of estradiol, Leading to increased endogenous FSH secretion (8).

The reduction in endometrial thickness among modalities containing $\mathrm{CC}$ is widely shown in the literature. The starting dose of clomiphene citrate is $50 \mathrm{mg}$ per day for 5 days, commencing between day 2 to 5 of menses (9).

Side effect include: reversible ovarian enlargement, visual symptoms (blurred vision, double vision, floaters, eye sensitivity to light, scotomata), headache, vasomotor flushes, abnormal uterine bleeding and abdominal discomfort. High blood level of triglycerides, liver inflammation, reversible baldness and or ovarian hyperstimulation syndrome (10).

Phytoestrogens were first observed in 1926 but it was unknown if they could have any effect in human or animal metabolism. In the 1940s, it was noticed for the first time that red clover (aphytoestrogens -rich plant) had effects on the fecundity of grazing sheep (11).

\section{Introduction .1}

Polycystic ovary syndrome (PCOS) is common endocrine disorder. The prevalence of this disorder is from $6 \%$ to $20 \%$ in women of reproductive age depending on the used diagnostic criteria (1). The prevalence of infertility in women with PCOS varies between 70 and $80 \%$ according to The American Society for Reproductive Medicine (2).

The simultaneous presence of polycystic ovary and an-ovulation was first recognized as distinct syndrome, by Irving Stein and Michael Leventhal in 1935 (3). The etiology of PCOS has not been fully explained, but is assumed to be multifactorial, comprising genetics, the intrauterine environment, and life style factors (4).

The clinical presentation is extremely variable hyperandrogenism, menstrual disorders (oligo-amenorrhea) and polycystic ovaries on ultrasound (5). Although pelvic ultrasound is a major diagnostic tool, it is not the only one (6). The diagnosis is straightforward using the Rotterdam criteria, even when the syndrome is associated with wide range of symptoms.

The up-to-date definition of PCOS (Rotterdam criteria 2004) requires at least two of the following clinical and endocrine features: chronic ovulatory disorder, hyperandrogenism and polycystic ovaries. Several methods have been effective for 
January 2018 and June 2018, on a total number of 100 women in reproductive age.

\section{Inclusion criteria:-}

1. Age: 18-38 years old.

2. Infertility (primary or secondary) for at leastlyear.

3. Diagnosis of PCOS was made according to Rotterdam criteria which is two of the following clinical and endocrine features: chronic ovulatory disorder, hyperandrogenism and polycystic ovaries.

\section{Exclusion criteria:-}

1.

Abnormal Husband's semen analysis

2 .

Abnormal uterine cavity or

abnormal tubes excluded by

hysterosalpingogram (HSG) .

$3 . \quad$ other conditions that can cause

chronic anovulation and androgen excess

such as:( hyperthyroidism, Congenital adrenal hyperplasia)

The study was Prospective randomized in Beni Suef University Hospital, It was included two groups; Group one : Included 50 patient with PCOS will receive $\mathrm{CC}$ from third day of cycle for five days, Group two: Included 50 patient with PCOS will receive $\mathrm{CC}$ from 3rd of cycle for 5 days plus phytoestrogen (Klimadynon( $(\mathbb{R})$, Bionorica, Neumarkt i.d.OBf., Germany) (20mg of cimifuga racemosa from day 1to12).
They are adverse group of naturally occurring non-steroidal plant compounds that have the ability to cause estrogenic and antiestrogenic effect because of their structural similarity with estradiol (17-B-estradiol). Phytoestrogen are similar in chemical structure to the mammalian estrogen, estradiol, and bind to the specific receptor site known estrogen receptors alpha and beta with more preference to beta receptors (12).

It also modulates the concentration of endogenous estrogens by binding or inactivating some enzymes. (13).

Dose of phytoestrogen (Klimadynon) is $20 \mathrm{mg}$ of cimifugaracemose from day 1 to 12 . Phytoestrogen supplements have a safe side effect profile with moderately elevated rates of vaginal bleeding, endometrial hyperplasia, endometrial cancer and breast cancer were not significantly increased among phytoestrogen users (14).

The aim of the study to assess the effectiveness of phytoestrogen with clomiphene citrate for ovulation induction in women with polycystic ovarian syndrome to overcome the antiestrogenic effect of clomiphene citrate on endometrium

\section{Patients and Methods .2}

The study was carried out at department of obstetrics and gynecology clinic of Beni- Suef University Hospital in the period between 
- Descriptive statistics were produced for categorical data as the frequency and percentage and for quantitative data by mean $\pm \mathrm{SD}$.

- Comparisons between the groups were conducted by independent sample $\mathrm{T}$ test for parametric data and by Mann Whitney test for Non-parametric data. Chi-Square test was used to test the significance between groups regarding qualitative data.

- Bivariate correlations between the study variables were carried by calculating the Pearson's and Sperman's correlation coefficients.

Probability level (P-value) was assumed as

- $\quad \mathrm{P}>0.05$ : Non significant (NS)

- $\mathrm{P}<0.05$ : Significant (S)

- $\mathrm{P}<0.01$ : Highly significant (HS)

\section{Results .3}

Our study included 100 women with PCOS were randomly divided using automated web randomization system into groups:- Group one included 50 women received CC only $50 \mathrm{mg}$ orally started from day 3 for 5 days (9), Group two included 50 women received $\mathrm{CC} 50 \mathrm{mg}$ orally pluse phytoestrogen (Klimadynon( $(\circledR)$, Bionorica, Neumarkt i.d.OBf., Germany) (20mg of cimifuga racemosa from day 1to12).

\section{All the patients will be submitted to the}

\section{following steps:-}

-Informed consent taken from each patient. -Full history.

Each patient will be submitted for height and weight measurement for estimation of the body mass index as excessive weight is associated with adverse metabolic and reproductive health outcomes in women with PCOS. For instance, female fertility significantly decreases with a BMI $>30-32 \mathrm{~kg} / \mathrm{m}^{2}$ (15). General examination, abdominal examination.

\section{Investigations include:-}

\section{Imaging:}

Vaginal ultrasound for checking the presence of at least one ovary of 12 or more follicles with diameters of 2-9 $\mathrm{mm}$ and/or increase the ovarian size $>10 \mathrm{ml}$. also to measure endometrial thickness.

\section{Laboratory:}

FSH- LH-TSH- Prolactin- DHEAS Testosterone -17-Hydroxy progesterone at base line visit.

\section{Statistical methodology}

- Data were analyzed using Statistical Package for the Social Sciences (SPSS), Version 20.Graphics were done by Excel Microsoft office 2007. 
Table1: Baseline clinical characteristics of the study groups

\begin{tabular}{|l|c|c|c|}
\hline & CC alone (n= 50) & CC + Phytoestrogen (n= 50) & $p$ value \\
\hline Age (years) & $\begin{array}{c}3.3 \pm 26.7 \\
(33-20)\end{array}$ & $\begin{array}{c}4.2 \pm 26.5 \\
(36-20)\end{array}$ & (NS) 0.812 \\
\hline BMI $\left(\mathbf{k g} / \mathbf{m}^{2}\right)^{*}$ & $\begin{array}{c}2.1 \pm 27.4 \\
(32-25)\end{array}$ & $\begin{array}{c}1.7 \pm 27 \\
(30-24)\end{array}$ & (NS) 0.266 \\
\hline $\begin{array}{c}\text { Type of infertility: } \\
-\quad \text { Primary }^{\dagger}\end{array}$ & $\begin{array}{c}(52 \%) 26 \\
(48 \%) 24\end{array}$ & $\begin{array}{c}(54 \%) 27 \\
(46 \%) 23\end{array}$ & (NS) 0.841 \\
$-\quad$ Secondary & $\begin{array}{c}1.2 \pm 2.9 \\
(5-1)\end{array}$ & $\begin{array}{c}1.3 \pm 3.1 \\
(6-1)\end{array}$ & (NS) 0.503 \\
\hline $\begin{array}{l}\text { Duration } \\
\text { infertility (years) }^{*}\end{array}$ & & & \\
\hline
\end{tabular}

Data are described in mean \pm SD (range); $\dagger$ data are described in number of cases (\%); BMI: :* body mass index; NS: statistically insignificant; $S$ : statistically significant $(\mathrm{p}<0.05)$

There was no significant difference between the two group regarding age, BMI, duration and type of infertility and ultrasonographic picture of PCOS (Table1).

Figure (1) show a Comparison between two groups regarding age

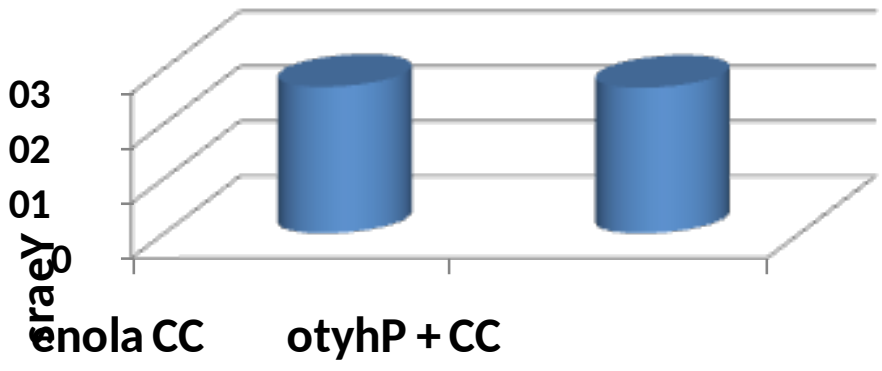

Figure (1): Mean age (years) between the study groups

Figure (2) show a Comparison between two groups regarding BMI 


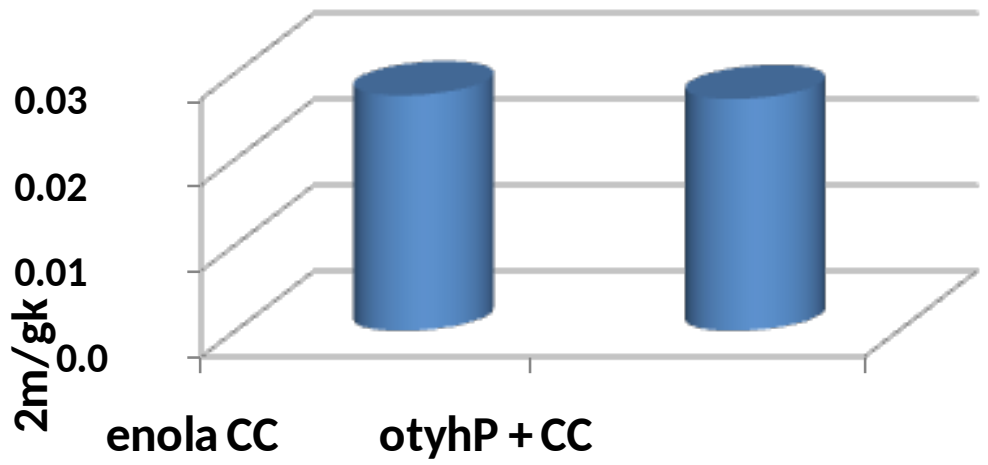

Figure (2): Mean BMI $\left(\mathrm{kg} / \mathrm{m}^{2}\right)$ between the study groups

Figure (3) show a Comparison between two groups regardingType of infertility

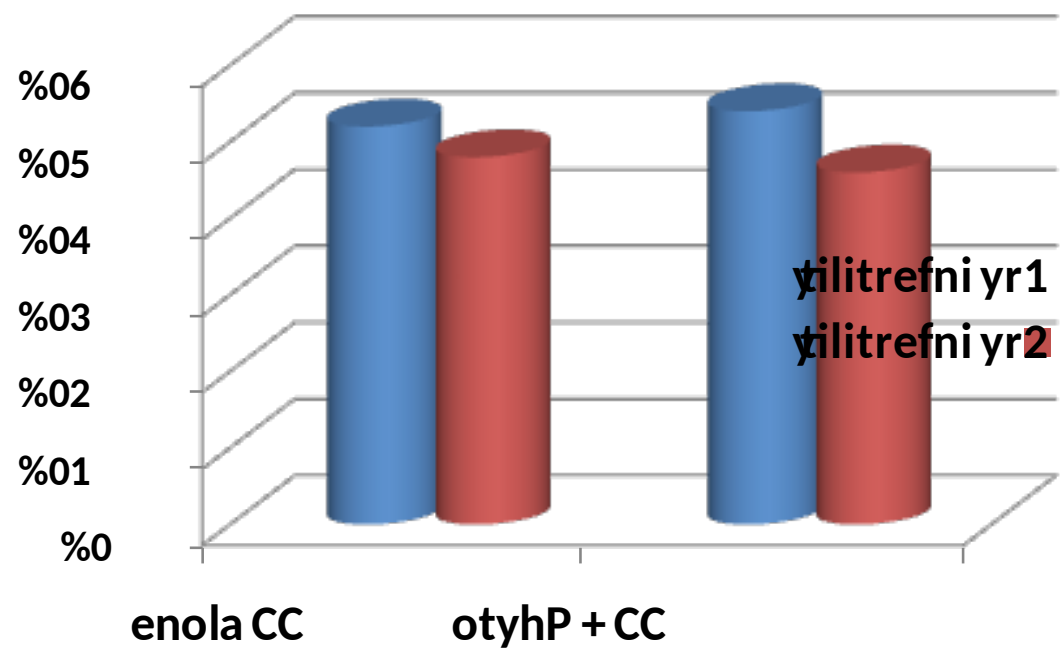

Figure (3): Type of infertility between the study groups

There was no significant difference between the two groups regarding age, BMI, duration and type of infertility

Table (2): Comparison between two groups regarding number of dominant follicles

\begin{tabular}{|l|l|l|l|l|l|}
\hline \multirow{2}{*}{} & \multicolumn{2}{|c|}{$\begin{array}{c}\text { CC alone } \\
(\mathbf{n = 5 0 )}\end{array}$} & \multicolumn{2}{c|}{$\begin{array}{c}\text { CC+ phytoestrogen } \\
(\mathbf{n}=\mathbf{5 0})\end{array}$} & \multirow{2}{*}{ P-Value } \\
\cline { 2 - 5 } & Range & Mean \pm SD & Range & Mean \pm SD & \\
\hline Number of dominant follicles & $0-3$ & \pm 1.01 .6 & $1-3$ & \pm 0.72 .2 & $(\mathrm{~S}) 002$. \\
\hline
\end{tabular}

*: Data are described in mean \pm SD (range); $\uparrow$ data are described in number of cases $(\%)$; NS: statistically insignificant; $\mathrm{S}$ : statistically significant $(\mathrm{p}<0.05)$

Table (2) shows a comparison between the groups regarding number of dominant follicles which was significant

In our study women received phytoestrogen plus $\mathrm{CC}$ had more dominant follicles than those who receive CC only $(2.2 \pm 0.7-1.6 \pm 1.0)$ respectively $\mathrm{P}$ value (.002). 
Figure (4) show a Comparison between two groups regarding number of dominant follicles

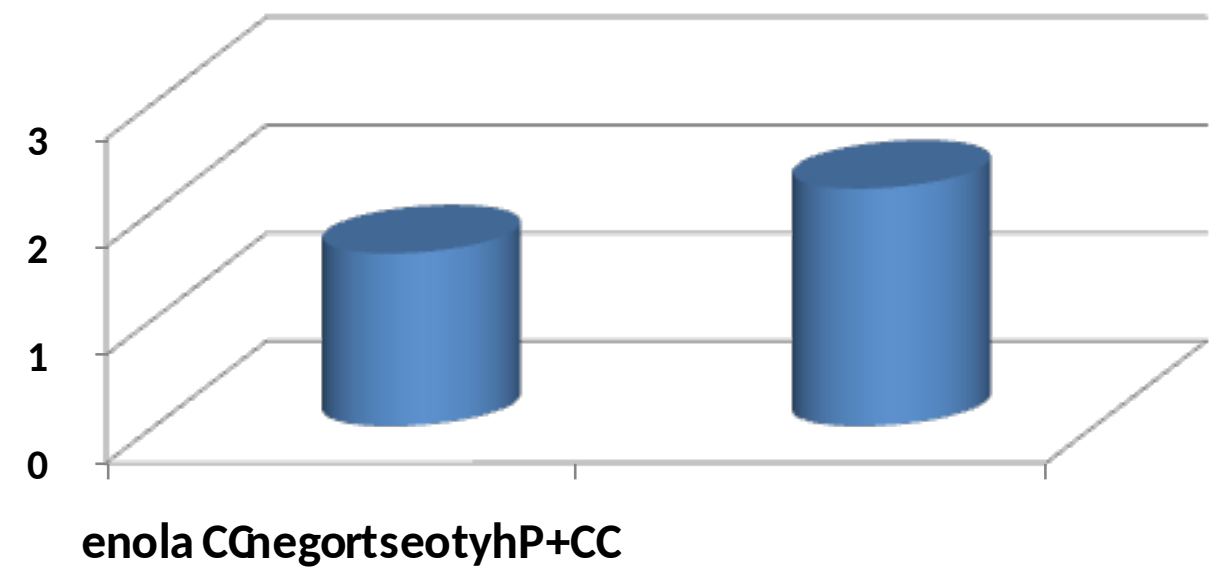

Figure (4): Mean number of dominant follicles between the study groups

Table (3): Comparison between two groups regarding endometrial thickness (mm)

\begin{tabular}{|l|l|l|l|l|l|}
\hline \multirow{2}{*}{ Endometrial thickness } & \multicolumn{2}{|l|}{ CC alone $(\mathbf{n}=\mathbf{5 0})$} & \multicolumn{2}{l|}{ CC+phytoestrogen $(\mathbf{n}=\mathbf{5 0})$} & \multirow{2}{*}{ P-Value } \\
\cline { 2 - 5 } & Range & Mean \pm SD & Range & Mean \pm SD & \\
\hline
\end{tabular}

Data are described in mean \pm SD (range); $\uparrow$ data are described in number of cases (\%); NS: :* statistically insignificant; $\mathrm{S}$ : statistically significant $(\mathrm{p}<0.05)$

Table (3) shows a comparison between the groups regarding endometrial thickness which was significant as women who receive phytoestrogen pluse $\mathrm{CC}$ had more thicker endometrium $(10.1 \pm 1.1)$ than those who receive CC only $(5.3 \pm .75) \mathrm{P}$ value $(<.001)$.

Figure (5) show a Comparison between two groups regarding endometrial thickness (mm)

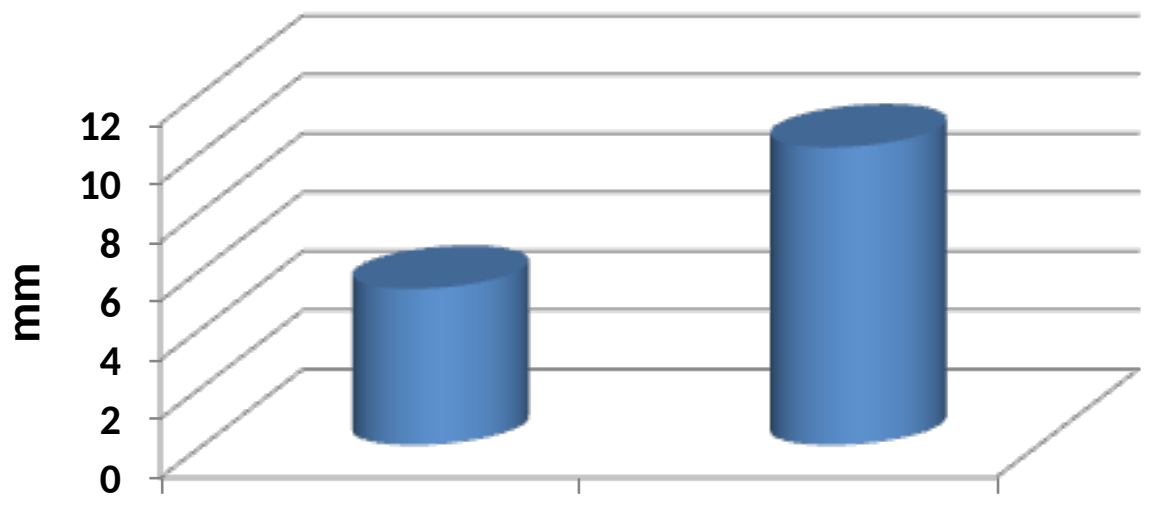

CC alone CC+Phytoestrogen 
Figure (5): Mean endometrial thickness between the study group

Table (4) : Comparison between two groups regarding ovulation rate

\begin{tabular}{|c|c|c|c|c|c|}
\hline \multirow{2}{*}{ Ovulation rate } & \multicolumn{2}{|c|}{$\mathbf{C C}$ alone $(\mathbf{n}=\mathbf{5 0})$} & \multicolumn{2}{c|}{$\mathbf{C C}+\mathbf{p h y t o e s t r o g e n ~}(\mathbf{n}=\mathbf{5 0})$} & \multirow{2}{*}{ P-Value } \\
\cline { 2 - 5 } & $\mathrm{NO}$ & $\%$ & $\mathrm{NO}$ & $\%$ & \\
\hline yes & 40 & $80 \%$ & 50 & $100 \%$ & $.001(\mathrm{~S})$ \\
\hline no & 10 & $20 \%$ & 0 & $0 \%$ & \\
\hline
\end{tabular}

*: Data are described in mean \pm SD (range); $\dagger$ data are described in number of cases (\%); NS: statistically insignificant; $S$ : statistically significant $(\mathrm{p}<0.05)$

Table (4) shows a comparison between the groups regarding ovulation rate which was significant as women who receive phytoestrogen plus $\mathrm{CC}$ had more ovulation rate more than those who receive CC only (100\%-80\%)respectively $\mathrm{P}$ value(.001).

Figure (6) show a Comparison between two groups regarding ovulation rate

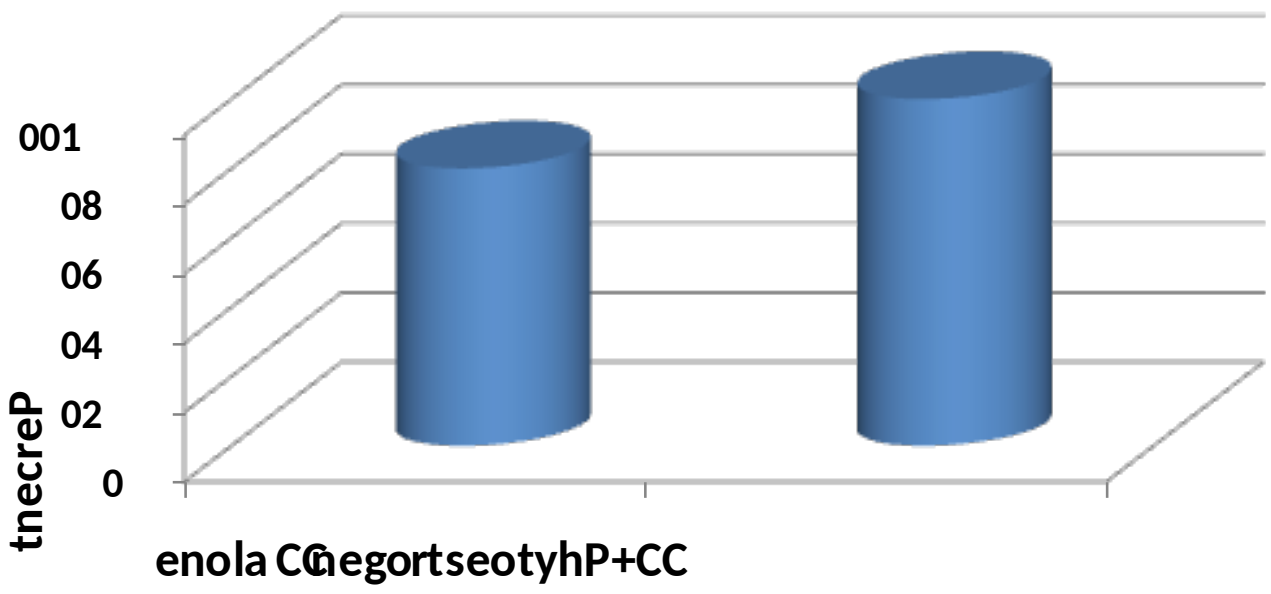

Figure (6): Ovulation rate between the study groups

Table (5): Comparison between two groups regarding pregnancy rate

\begin{tabular}{|c|c|c|c|c|c|}
\hline \multirow[t]{2}{*}{ Pregnancy rate } & \multicolumn{2}{|c|}{$\begin{array}{c}\text { CC alone } \\
(\mathbf{n}=50)\end{array}$} & \multicolumn{2}{|c|}{$\begin{array}{c}C C+p h y t o e s t r o g e n \\
(n=50)\end{array}$} & \multirow[t]{2}{*}{ PValue } \\
\hline & $\mathrm{NO}$ & $\%$ & $\mathrm{NO}$ & $\%$ & \\
\hline positive & 9 & $18 \%$ & 18 & $36 \%$ & \multirow[t]{2}{*}{$.043(\mathrm{~S})$} \\
\hline negative & 41 & $82 \%$ & 32 & $64 \%$ & \\
\hline
\end{tabular}

$*$ : Data are described in mean \pm SD (range); $\dagger$ data are described in number of cases (\%); NS: statistically insignificant; $\mathrm{S}$ : statistically significant $(\mathrm{p}<0.05)$

Table (5) shows a comparison between the two groups regarding pregnancy rate which was significant as women who receive phytoestrogen plus CC had more pregnancy rate than those .who receive CC only (36\%-18\%)respectively $\mathrm{P}$ value(.043)

Figure (7) show Pregnancy rate in CC only group 


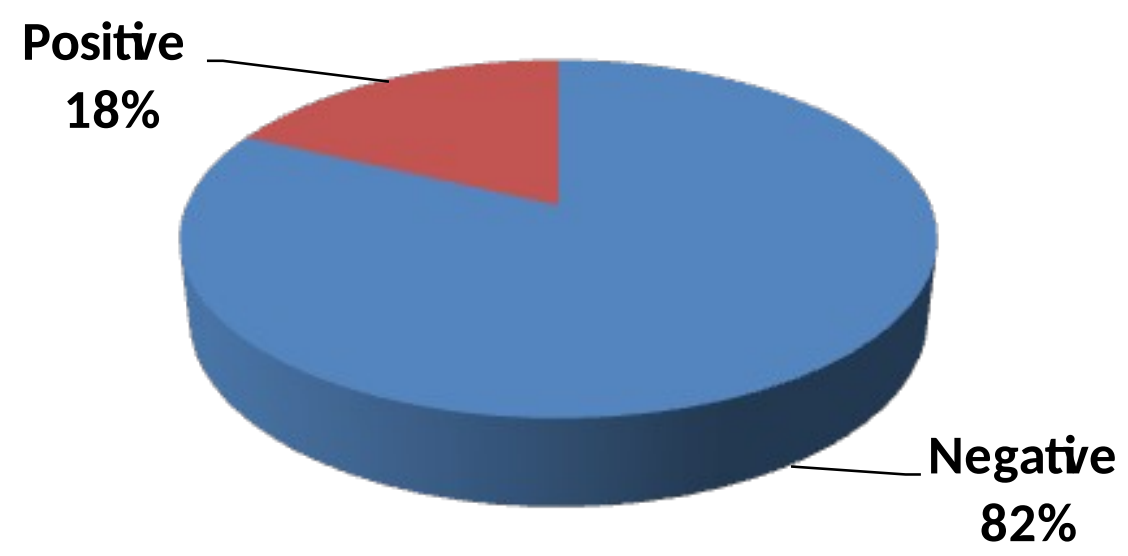

Figure (7): Pregnancy rate in CC only group

Figure (8) show Pregnancy rate in $\mathrm{CC}+$ phytoestrogen only group

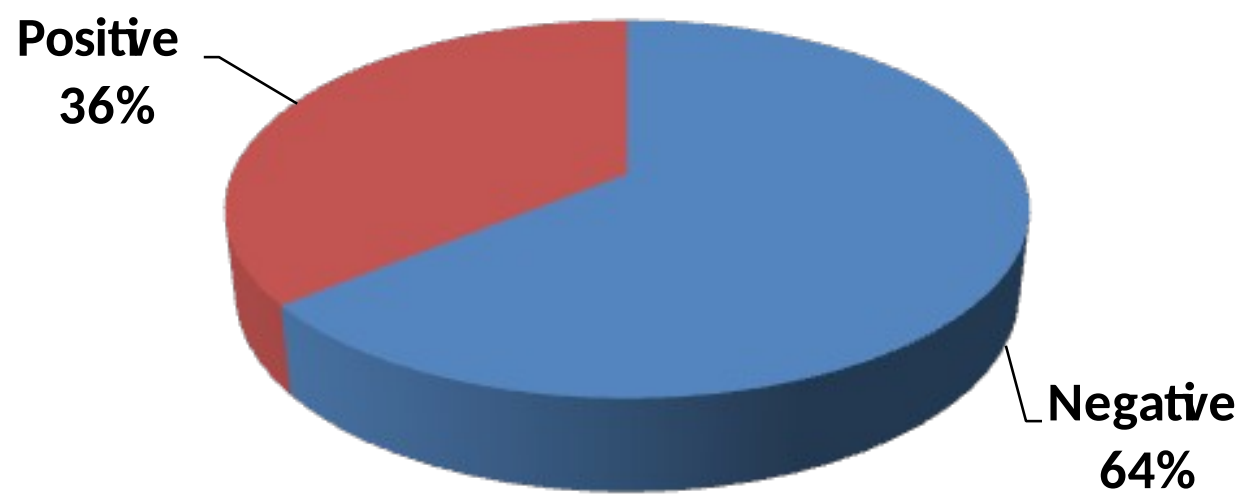

Figure (8): Pregnancy rate in $\mathrm{CC}+$ phytoestrogen 
This was agreed study done by Shahin and Mohamed (16). as age was $25.3 \pm 3.1$ in group one and $25.3 \pm 3.4$ in group two. Also it was agreed with study done by Ahmed Maged as age was 28.4 in group one and 28.38 in group two (17).

Concerning patient BMI in both groups, the mean of group one was $27.4 \pm 2.1$, the mean group two was27.1 \pm 1.7 , There was no statistically significant difference between both groups .this was agreed with study done by Shahin and Mohamed (16) as BMI in group one was $26 \pm 1.4$ and in group to was $27 \pm 2.1$ which was no statistically significant difference.

Concerning patient type of infertility in both groups, the mean of group one was 26 case with 1ry infertility and 24 case with secondary infertility, the mean group two was 27 case with 1ry infertility and 23 case with secondary infertility, There was no statistically significant difference between both groups ..

Our study showed that women received phytoestrogen had more thicker endometrium $(10.1 \pm 1.1)$ than those who receive CC only (5.3 $\pm .75) \mathrm{P}$ value(.001). This was in agreement with study done by Shahin and Mohamed. (16). Theyt studied patients less than 35 years, presenting with infertility and PCOS, were included and randomly allocated to either group I (clomiphene citrate; CC) or group II (CC plus Cimicifugaeracemosae; CR. Analysis included 98 patients in group I versus 96 patients in

\section{Discussion-4}

Polycystic ovary syndrome (PCOS) is a common endocrine disorder. The prevalence of this disorder is from $6 \%$ to $20 \%$ in women of reproductive age depending on the diagnostic criteria used (1). The prevalence of infertility in women with PCOS varies between $70 \%$ and $80 \%$ according to The American Society for Reproductive Medicine (2). It has been more than 50 years that $\mathrm{CC}$ is established as the first line for ovulation induction in PCOS. it is believed to be more convenient and costefficient (7).

Adding Phytoestrogen plant compounds to $\mathrm{CC}$ in women with PCOS improve endometrial thickness, ovulation rate and pregnancy rate.

Our study aimed to assess the effectiveness of phytoestrogen with clomiphene citrate for ovulation induction in women with polycystic ovarian syndrome to overcome the antiestrogenic effect of clomiphene on endometrium. The study divided in to two groups. Both groups were matched in general characteristics as age(year) and BMI (Kg/ $\mathrm{m}^{2}$ )Concerning patient age in both groups, the mean of group one was $26.7 \pm 3.3$, the mean of group two was $26.5 \pm 4.2$. There was no statistically significant difference between both groups. 
randomized them into two equal groups the first group received $100 \mathrm{mg}$ of CC per day for 5 days while the second group were subjected to $20 \mathrm{mg}$ of Cimicifugaracimosa extract (Klimadynon) for 10 successive days. The two study groups showed no significant differences regarding demographic data as age or clinically presenting symptoms or hormonal profile measured before .the start of the medications

It showed significant improvement in endometrial thickness in Cimicifugaracimosa extract group $(\mathrm{p}=0.0004)$. He concluded that the use of Phyto-oestrogen is a good alternative to clomiphene citrate for ovulation induction in .women with PCOS

This was in agreement with study done by Unfer et al. (19) who evaluated the effect of adding phytoestrogens to $\mathrm{CC}$ in induction of ovulation in infertile women subjected to treatment with intrauterine insemination. They selected 134 women complaining of infertility for 2 years or more with their age ranged from 25 to 35 years. All participants had menstrual irregularities in the form of oligomenorrhea or amenorrhea but they all were responsive to progesterone withdrawal test. They randomly classified them into 2 equal groups, group 1 received CC only and group 2 added phytoestrogens to CC. All participants showed increased hormonal levels of FSH, LH and 17- $\beta$ estradiol in plasma. There was no significant difference between the 2 study. They found a group II. Both groups were matched regarding demographics and basic data. Significant differences were elicited regarding endometrial thickness $(\mathrm{mm})(8.5 \pm 1.9$ versus $12.5 \pm 1.9, \mathrm{p}$ $.<0.001)$

Also, Shahin and Mohamed (16) randomly classified 134 women with unexplained infertility treated by induction of ovulation using CC into 2 equal groups. Group 1 added phytoestrogen (PE) to CC and group 2 added ethinyloestradiol (EE) to CC during the proliferative phase

Women in PE group showed better endometrial thickness $(\mathrm{P}<0.001)$. They reached the conclusion that phytoestrogens administered in high doses have the ability to reverse the adverse effects of $\mathrm{CC}$ on endometrial thickness with contribution to higher pregnancy rates. They concluded that addition of PE during the follicular phase to $\mathrm{CC}$ in women with unexplained infertility under treatment of CC ovulation induction and timed natural intercourse markedly improved the cycle characteristics in unexplained infertility women treated with clomiphene citrate induction and timed intercourse when compared with EE .supplementation (16)

ALSO this was in agreement with study done by Kamel (18). Kamel performed a study to evaluate the effects of a phyto-oestrogen, Cimicifugaracimosa extract in induction of ovulation in 100 patients with PCOS. He 
Cimicifugaeracemosae; CR. Analysis included 98 patients in group I versus 96 patients in group II. Both groups were matched regarding demographics and basic data. Phytoestrogen plus CC group had significantly higher clinical pregnancies per cycle (33/192 (17.2\%) versus $71 / 204(34.8 \%), \mathrm{p}<0.01)$, compared to the $\mathrm{CC}$ only group. This was in disagreement with . study done by Kamel (18)

A higher but clinically insignificant pregnancy rate was found in .Cimicifugaracimosa extract group This was in disagreement with study done Shahin and colleagues randomly classified 134 women with unexplained infertility treated by induction of ovulation using CC into 2 equal groups. Group 1 added phytoestrogen (PE) to $\mathrm{CC}$ and group 2 added ethinyloestradiol (EE) to .CC during the proliferative phase

The clinical pregnancy rate showed no statistically significant difference between the 2 groups (14.0\% versus $21.1 \%$, respectively) They concluded that addition of PE during the follicular phase to $\mathrm{CC}$ in women with unexplained infertility under treatment of CC ovulation induction and timed natural intercourse markedly improved the cycle characteristics in unexplained infertility women treated with clomiphene citrate induction and timed intercourse when compared with EE .supplementation (16) statistically significant difference between the 2 groups regarding endometrial thickness being .thicker in group 2

In our study women received phytoestrogen had more dominant follicles than those who receive CC only (2.2 $\pm .7-1.6 \pm 1)$ respectively $\mathrm{P}$ value (.002).

In our study women received phytoestrogen had more ovulation rate than those who receive CC only (100\%-80\%) respectively $\mathrm{P}$ value (.001).

ALSO this was in agreement with study done by Kamel (18) who performed a study to evaluate the effects of a phyto-oestrogen, Cimicifugaracimosa extract in induction of ovulation in 100 patients with PCOS. He randomized them into two equal groups the first group received $100 \mathrm{mg}$ of CC per day for 5 days while the second group were subjected to $20 \mathrm{mg}$ of Cimicifugaracimosa extract (Klimadynon) for 10 successive days. The women in the second group had a significant improvement in .ovulation than CC group $(\mathrm{p}=0.0001)$ In our study women received phytoestrogen had more pregnancy rate than those who receive CC only (36\%-18\%) respectively $\mathrm{P}$ value (.043). This was in agreement with study done by Shahin and Mohamed (16). They studied patients less than 35 presenting with infertility and PCOS, were included and randomly allocated to either group I (clomiphene citrate; CC) or group II (CC plus 
Metabolism-Clinical and Experimental, We conducted that adding phytoestrogen to 2016; 65 (5): 776-82.

CC have increase number of dominant follicles,

FertilSteri I. Practice Committee of .2 endometrial thickness with improvement of both American Society for .ovulation rate and pregnancy rate

Reproductive Medicine. Definitions of

\section{Conclusion and Recommendations}

infertility and recurrent pregnancy loss. a

We conducted that adding phytoestrogen to .committee opinion, 2013; 99(1): 63

3.Porcaro G, Bizzarri M, Monastra G et al.

Strategies for the treatment of polycystic ovary syndrome (PCOS) women : the role of myo-inositol (MI) and d-chiro-inositol (DCI) between diet and therapy .In CobbsB, ed polycystic ovary syndrome (PCOS):clinical aspects, potential complication and dietary management. Huppauge, NY: Nova science publishers.2016, in press

4.Dumesic DA, Oberfield SE, Stener-Victorin E, et al. Scientific Statement on the Diagnostic Criteria, Epidemiology, Pathophysiology, and Molecular Genetics of Polycystic Ovary Syndrome. Endocr Rev, 2015; 36(5): 487-525.

5.Fauser BC, Tarlatzis BC, Rebar RW, et al. Consensus on women's health aspects of polycystic ovary syndrome (PCOS): the Amsterdam ESHRFJASRM-Sponsored 3rd PCOS Consensus Workshop Group. Fertil Steril, 2012; 97:28-38.

6. Marrinan, Lin G, Eugene C, ed. "Imaging in polycystic Ovary Disease". eMedicine. Retrieved 19 November 2011 $\mathrm{CC}$ have increase number of dominant follicles, endometrial thickness with improvement of both ovulation rate and pregnancy rate.

In this study we founded that adding phytoestrogen to clomiphene citrate in patient with PCOS improve endometrial thickness with improvement of both ovulation rate and pregnancy rate.so we advise to do further study and give phytoestrogen with clomiphene citrate in patient with PCOS with un explained infertility to show if there is improvement in endometrial thickness.

However, our study has limitations, including small sample sizes and short duration. The benefits from using of phytoestrogen in treatment of PCOS remain to be defined by future studies. Meanwhile, more randomized, double-blind, large sample size. Trials of phytoestrogen for PCOS are needed in the future to confirm or modify the result of this work.

\section{References}

1. Echiburu B, Crisosto N, Maliqueo M, et al. Metabolic profile in women with polycystic ovary syndrome across adult life. 
evidence-based guideline. Development Groups Med J Aust, 2011; 195(6):S65-112.

16.Shahin AY and Mohammed SA. Adding the phytoestrogen CimicifugaeRacemosae to clomiphene induction cycles with timed intercourse in polycystic ovary syndrome improves cycle outcomes and pregnancy rates-a randomized trial. Gynecol Endocrinol, 2014; Mar 5.

17.Maged A. Phytoestrogens as an alternative to estradiol in reversing the antiestrogenic effect of clomid on endometrium in ovulation induction in cases of polycystic ovarian syndrome (PCOS). 2015.

18. Kamel HH. Role of phyto-oestrogens in ovulation induction in women with polycystic ovarian syndrome. Eur J Obstet Gynecol Reprod Biol 2013; 168(1):60-63.

19.Unfer V, Casini ML, Costabile L, et al. High dose of phytoestrogens can reverse the antiestrogenic effects of clomiphene citrate on the endometrium in patients undergoing intrauterine insemination: a randomized trial. J Soc Gynecol Investig, 2004; 11:5:323-328.
7.Spritzer PM, Motta AB, Sir-Petermann T, et al. Novel strategies in the management of polycystic ovary syndrome. Minerva Endocrinol. 2015; 40:195-212.

8.Gorthi S, Balen AH, Tang T. Current issues in ovulation induction Obstet Gynaecol, 2012; 14:188-96.

9. Wu CH and Winkel CA. The effect of therapy initiation day on clomiphene citrate therapy .Fertil Steril, 1989; 52:5648.

10.Emre S. "Ovulation induction with clomiphene citrate". Up-to-date Retrieved 21 April 2014.

11. Yildiz F. Phytoestrogens in Functional Foods. Taylor \& Francis Ltd; 2005: 3-5: 210-211.

12.Paterni I, Granchi C, Katzenellenbogen,et al.Estrogenreceptors alpha $(\mathrm{ER} \alpha)$ and beta (ER $\beta)$ : subtype- selective ligands and clinical potential. Steroids, 2014; 128X (14): 00151-00152.

13.Johnston I. Phytochem Functional Foods. Boca Raton, Florida: CRC Press Inc.; 2003: 66-68

14.Tempfer CB, Froese G, Heinze G, et al. Side effects of phytoestrogens: A meta-analysis of randomized trials. Am J Med, 2009; 122(10): 939-946.

15.Teede HJ, Misso ML, Deeks AA, et al. Guideline. Assessment and management of polycystic ovary syndrome: summary of an 
